OPEN ACCESS

International Journal of Applied Research in Social Sciences

Vol. 1(4), pp. 124-137, July, 2019

Fair East Publishers

Journal Homepage: www.fepbl.com/index.php/ijarss

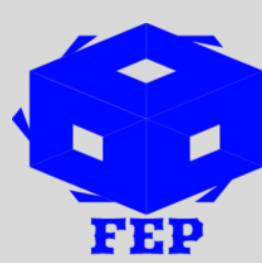

\title{
DEVELOPING THE INFORMATION TECHNOLOGY APPLICATION COMPETENCE OF TEACHERS IN ONLINE TEACHING
}

\author{
Thanh Chi Phan ${ }^{1}$, Thanh Tu Ngo ${ }^{2}$, Tien Minh Phan ${ }^{3}$ \\ ${ }^{1}$ Quang Tri Teacher Training College, PhD Candidate Ha Noi University of Science and \\ Technology, Vietnam. \\ ${ }^{2} \mathrm{Ha}$ Noi University of Science and Technology, Vietnam. \\ ${ }^{3}$ Hue University of Education, Vietnam.
}

*Corresponding: Thanh Chi Phan

${ }^{1}$ Corresponding Email: thanhpc.sp@ gmail.com

Article Received: $18-05-19$ Accepted: 15-07-19

Published: 05-08-19

Licensing Details: Author retains the right of this article. The article is distributed under the terms of the Creative Commons Attribution-NonCommercial 4.0 License (http://www.creativecommons.org/licences/by-nc/4.0/) which permits non-commercial use, reproduction and distribution of the work without further permission provided the original work is attributed as specified on the Journal open access page.

\begin{abstract}
Developing the competence to use information technology in teaching is one of the important occupational competencies for teachers in the digital age. Information technology application development has many implications in promoting the training process to train and develop students, in accordance with the actual conditions of education in Vietnam and the general trend of the world is essential.

Research paper on needs assessment using information technology of teachers in online teaching, proposing the process of identifying the structure of information technology competencies and requirements for capacity development to use information technology in online teaching of training institutions. The parameters in this paper present an empirical research result to address the need to develop the information technology application competence in online teaching, necessary to successful organize online teaching with a variety of theoretical and practical pedagogies in technology in education.
\end{abstract}

Keywords: information technology competence, information technology application competence, online teaching 


\section{INTRODUCTION}

Applying information technology (IT) in teaching in general and in online teaching in particular is an indispensable trend in the digital age. Many research results show that the integration of technology has many benefits for both teachers and students in the teaching process. By studying the impact of IT application competence in teaching by analyzing and compiling information from related scientific publications conducted in different countries, the authors give that IT application enhances cognitive ability, self-learning ability of students (Bennett, J., et. al, 2006). Therefore, in addition to the teachers need IT competence to improve the quality of teaching activities of themselves, teachers can shape and develop IT competence for students through training.

The research was developed and distributed to experienced online teachers to assess the importance of a list of online teaching tasks with a 7-point Likert measuring tool (Paula, M. B., et. al., 2010). Effective online course development depends on: 1) course content is set good design, the interaction between teachers and learners, the teachers are well prepared and fully supported; 2) create a sense of online learning community; and 3) the rapid advancement of technology (Sun, A., \& Chen, X., 2016), which demonstrates the impact of technology that brings fundamental success in online teaching and is essential in organizing and implementing courses.

The research on developing the IT application competence of teachers in online teaching has many theoretical and practical meanings. Applying the IT competence structure in teaching can support the assessment of applicability and give the right direction in using, fostering and developing IT competence for teachers in online teaching in the context digital age.

\section{Definition of IT competence in teaching}

\section{LITERATURE REVIEW}

By analyzing the concepts of competence, competence can be defined by categories: activity category (competence is the mobilization of knowledge, skills and other personal attributes excitement, belief, will ... to perform a certain type of work in a given context (Education and Training Ministry, 2015); Category of individual attributes (Competence is the characteristic of an individual who demonstrates the level of proficiency - ie, can be practiced successfully and certainly - one or several types of activity (Institute of Linguistics, 2010). Although there are differences in the use of terminology, the commonality of these concepts is that the two characteristics of competence are the competence that is expressed through action and ensures effective operation, good results.

The term IT is defined as a set of modern scientific, technological and technical tools for the production, transmission, collection, processing, storage and retrieval of information. exchange of digital information (National Assembly of Vietnam, 2006). IT competence is defined as a diverse set of tools and technology resources used to exchange, create, disseminate, store and manage information (Craig Blurton, 2002).

The concept of IT competence in teaching is understood to be the storage, processing, and communication of information by means of electronic means, and through such means to communicate, and communicate information between many people or group together effectively in the teaching process. 


\section{Some IT competence structures in teaching According to UNESCO}

In 2011, the United Nations Educational, Scientific and Cultural Organization (UNESCO) set up an Information Communication Technology (ICT) Competence Framework for Teachers, in which the competence framework covers 6 dimensions (UNESCO, 2011). In teaching, the teachers include: (1) Understanding ICT in Education, (2) Curriculum and Assessment, (3) Pedagogy, (4) ICT, (5) Organization and Administration, (6) Teacher Professional Learning

In 2018, UNESCO set up an ICT Competence Framework for Teachers, in which the competence framework covers 6 dimensions. Each aspect consists of 3 levels of continuity in the development of teacher competencies (UNESCO, 2018):

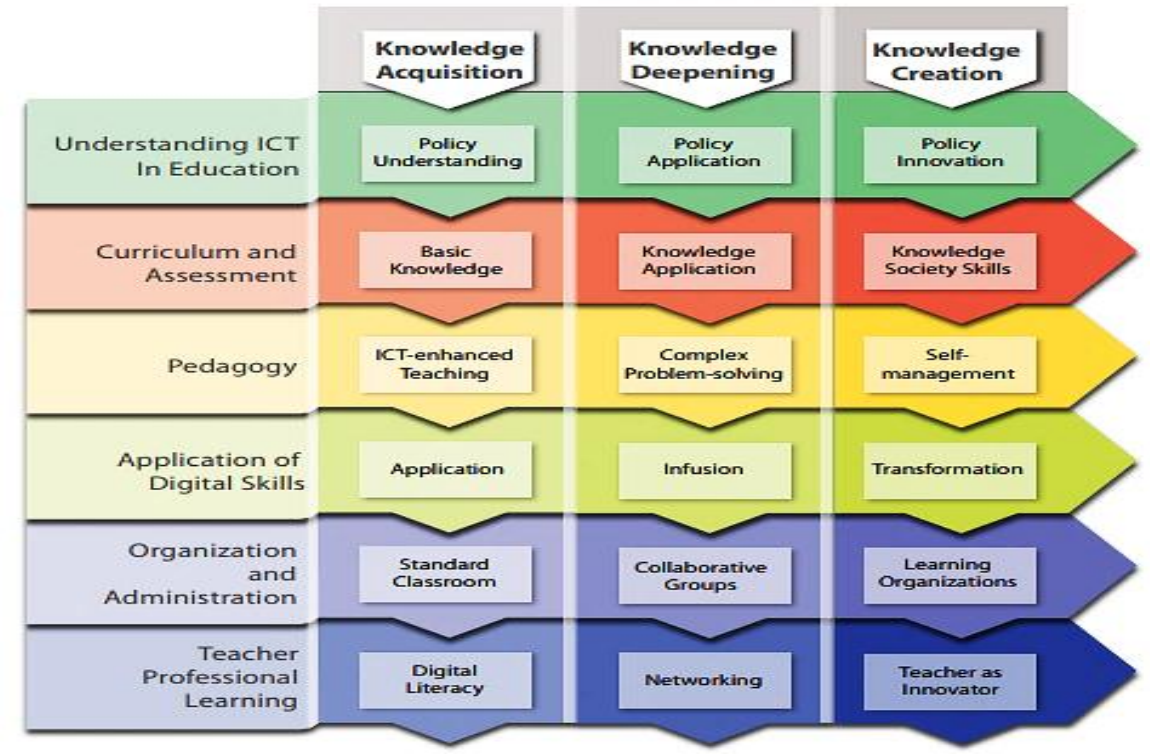

Figure 1: ICT competence for UNESCO's Teachers (UNESCO, 2018)

Assessment: The competence framework proposed by UNESCO in 6 dimensions is very diverse, not only in terms of tool use but also in theoretical knowledge, using those tools in activities specific of the teacher. In addition, the demand for IT competence in teaching for teachers is not limited to the proficient and effective use of what is available, but also encourages innovation, creating new ones based on the practice requirements of the teaching process.

\section{ISTE's technology skills standard for teachers}

In 2008, the International Society for Technology in Education (ISTE) published a set of standards for technology skills for teachers including five standards (ISTE, 2008). This standard defines the skills and pedagogical ideas that educators need in the digital age.

What is unique about this scale is that the application of IT is not limited to the skill level of using technology in different fields, but also emphasizes theoretical, practical and critical understanding. It also mentions the positive attitude, the correctness, and leadership when using digital tools and resources in schools.

\section{IT competence structures in teaching in Vietnam}

In 2011, a standard set of IT competencies for pedagogical students (based on UNESCO's IT competence standards for teachers) was consulted at the "UNESCO ICT Program" workshop 
with 6 component competence and 3 levels of development (VVOB, 2011). The advantage of this standard is that it describes the specific expression of most levels in each criterion. However, some of the criteria in this standard are case-by-case.

\section{METHODOLOGY AND RESULTS Current Situation of IT Application in Teaching Situation of education policy}

In recent years, in implementing the policy of the government, the schools have been strengthened to equip IT systems and equipment in teaching support such as: computer lab, administration computer room, ICT equipment, the Internet and some other technological equipments create the IT infrastructure for teachers and students to use effectively in teaching. The development of software technology, in that the educational software actively supports the teaching process such as editorial and instructional support packages, e-learning, packaging software, open source code software and other utilities are also effectively exploited in teaching.

\section{Practical survey}

Surveyed on 110 teachers teaching at colleges and universities in Vietnam. Survey forms: questionnaires, live interviews and online surveys (via google docs forms, zalo, and other media).

The results of the analysis conducted through the survey factors of the demand for using IT in teaching as follows:

+ The attitude of teachers the use of IT in teaching: $86 \%$ of teachers surveyed said that they are interested in applying IT in teaching. In that, nearly a quarter of teachers feel uncomfortable using the technology tools in teaching, and more than half teachers only feel somewhat confident when applying technology.

Through analysis data, can be said that the majority of teachers have positive attitude and awareness with the application of IT in teaching. However, the fact that teachers feel the ability to use technology themself is limited to helping teachers feel confident and capable to integrate technology in teaching is urgent task and necessary for the education.

+ Level of teachers using IT in teaching and communication: Survey results show that most teachers have used the Internet as a tool to support information search to improve professional skills, but still some teachers have not fully utilized the Internet. In addition, teachers have used various forms of communication such as email, forums, social network sites to communicate effectively with colleagues. Nearly half of the surveyed teachers said that they not often used communication technologies. One point worth noting is that the majority of teachers sometimes integrate modern technology into their lectures and only about $8 \%$ of lecturers use it very often.

+ The need for IT competence framework in teaching: The issues to be investigated include: (1) the urgency of the introduction of using IT competence framework for teachers, (2) Self-assessment of proficiency the use of IT equipments in teaching, (3) Assessment of coherence between teaching methods and the use of IT in teaching, (4) Assessment the level of IT application in teaching, from data storage, communication to the exploitation of online resources to teach.

Analyze the results from the survey by teacher's attitudes: 
(1). Attitude of the teacher on the necessity of the IT competence framework: $95 \%$ think that there should be a standard IT competence framework use in teaching. However, only $65 \%$ of survey respondents were able to use the basic IT equipments in teaching, which suggests that the use of basic IT equipments is not an easy problem for teachers.

(2). Attitude of teachers on technology integration with pedagogical methods: For combining the teaching methods and IT application in teaching, with 3 levels of assessment: Very necessary (62\%), Need (32\%), No need (6\%).

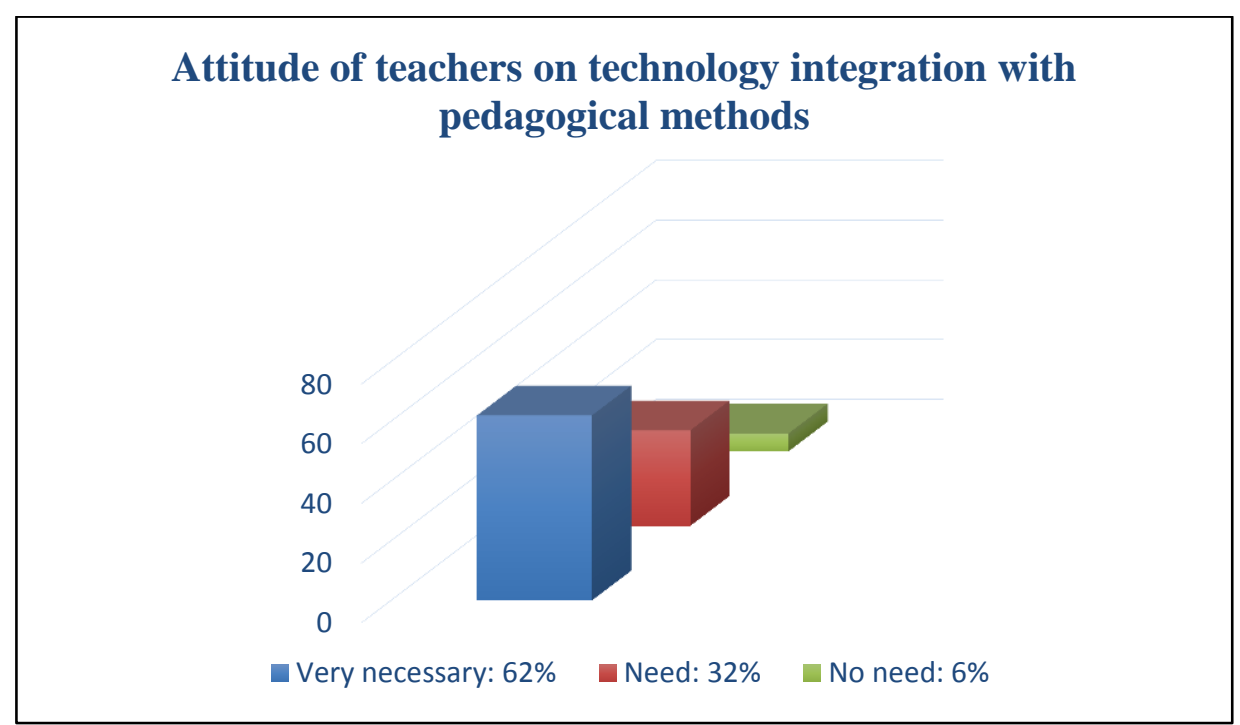

Figure 2: Attitude of teachers on technology integration with pedagogical methods

(3). Assessment of the level of using IT in teaching, from data storage, communication to resource mining to teaching; the level of teachers using technology to improve communication and teaching effectiveness: Level of using IT resources to improve effectiveness in teaching, with 3 levels: Regular (42\%), Sometimes (44\%), No (14\%). Level of using IT to contact colleagues, sharing documents, with 3 levels: Regular (52\%), Sometimes $(40 \%)$, None $(8 \%)$. Level of using IT to store information in teaching, with 3 levels: Regular (67\%), Sometimes (32\%), No (1\%).

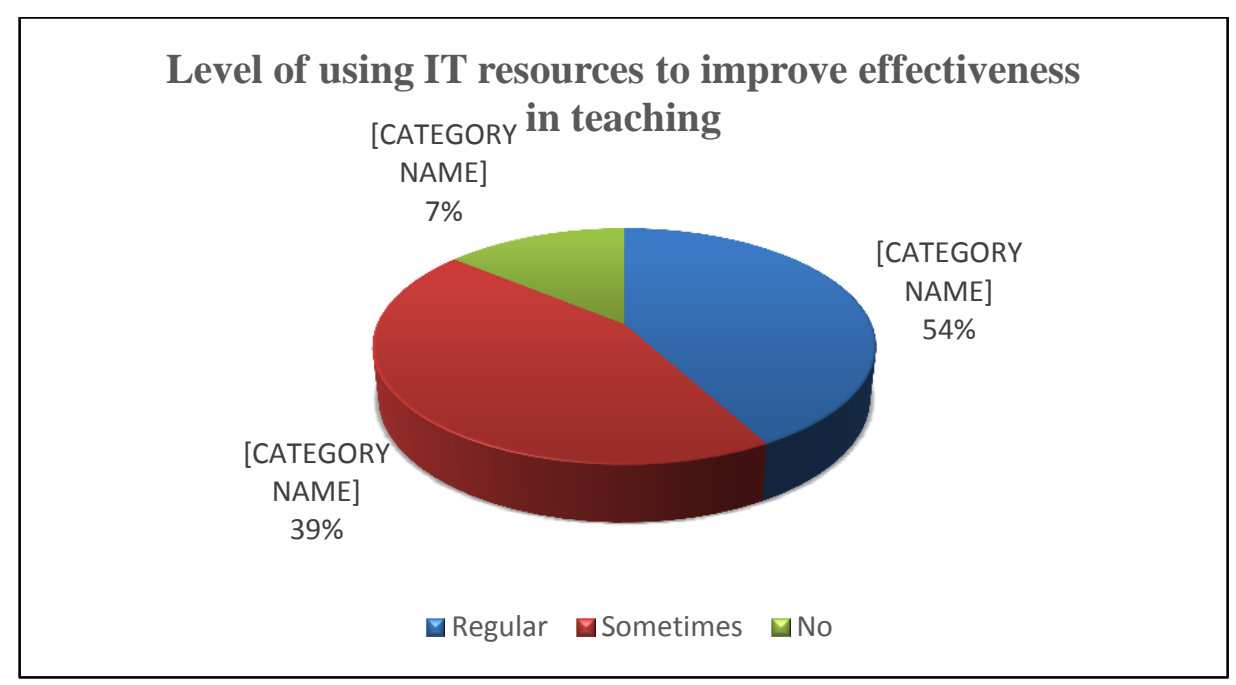

Figure 3: The levels of using IT in teaching 
Assessment: Most teachers are aware of the importance of applying IT in teaching with the trend of digital age; There should be a standard framework for assessing of using IT competence for teachers; Instructors need to know the combination of teaching methods and the use of IT in teaching; Teachers need to know how to use IT to store, communicate with colleagues, and use IT resources to improve their teaching effectiveness.

\section{Identifying the Using IT Competence in Online Teaching Principles of Identifying Competence in Online Teaching}

Online teaching is faculty-delivered instruction via the Internet. Online instruction includes real-time (synchronous) and anytime, anywhere (asynchronous) interactions.

A number of studies show that teaching methods are effective in online learning environments with the organizational and competence requirements for online courses. Online teaching, online education, online tutorials and online courses are used interchangeably in the online teaching methodology (Sun, A., \& Chen, X., 2016).

Gascoigne \& Parnell researched in technology and teaching methods that focus on core skills in online teaching organization, including: (1) technology, (2) pedagogy, (3) administrative competence (Gascoigne, C. \& Parnell, J, 2014).

+ Technology and social communication skills: Technological skills are fundamental, and although social communication skills are not essential, it enhances the ability to connect with the instructor's students. Skills include: basic computer skills, proficiency in software applications, software installation/updating, and additional, internet search capabilities, proficiency with features, communication platforms and functions in the learning management system.

+ Management and organizational skills: Skills such as time management, providing constructive feedback on students' assignments, proficiency in the content of the course and the ability to submit grades upon request, in accordance with track academic integrity issues.

+ Pedagogical skills and teaching methods: Centralized learning models, content-guided instruction and learning guides do not provide content, provide feedback on building, establishing and maintaining online presence.

Paula Bigatel have identified the potential for success in online teaching, which 7-point rule of effective teaching with an online teaching success: 1). Encourage contact between students and faculty; 2). Develop reciprocity and cooperation among students; 3). Encourage active learning; 4). Give prompt feedback; 5). Emphasize time on task; 6). Communicate high expectations; 7). Respect diverse talents and ways of learning (Paula, M., B., et al., 2010).

Teacher needs competence: In the knowledge creation approach will be able to design learning based on IT resources and environment; use IT to support the development of knowledge creation and critical thinking skills of students; assists students continuously, effectively learning and creating knowledge communities for students and colleagues.

\section{The Criteria for Assessing IT Application in Online Teaching}

By analyzing the research on the success of online teaching with the support of IT, the author proposes key criteria in assessing IT for teaching to guide the development of competence. The use of IT in online teaching is required, including:

a. Knowledge content standards

1). Exactly about subject science, about ideology. 
2). Qualified and fully meet the learning objectives; systematic; right emphasis.

3). Practical, relevant and educational relationships; Using the illustrations for the electronic lecture (multimedia, text, film, sound, images, supporting software, etc.) is accurate, meaningful, close to the content of the lesson, at the correct dose quantity.

4). Integrated, interactive learning environment.

\section{b. Method standards}

1). The teaching method is appropriate to the specific subjects, training.

2). Incorporation of methods in teaching and learning activities; To combine well the application of IT with teaching methods suitable with online content.

$3)$. Promote the competence of learners through online learning.

c. Vehicle and technical standards

1). Select appropriate teaching aids and techniques.

2). To combine well the use of means for electronic lectures and other teaching aids and equipment suitable with the content of online lessons.

3). Design of science lesson modules, in line with the subject's characteristics; Exploitation of teaching aids to ensure systematic, structured and clear procedures.

4). Effectively exploit the equipment and features used in the technology of the device.

d. Classroom management and organization standards

1). Organize and implement flexible promotion, distribution of reasonable time in the parts, stages in the lesson.

2). Organize and control learners actively and proactively in accordance with the content of online lessons; Ensure multi-dimensional interaction between teacher and learner.

3). To develop a mechanism for organizing and managing the teaching process according to the model of online learning.

e. Results and efficiency standards

1). Determining the using of IT competence helps teachers to organize positive teaching activities, contributing to the innovation of teaching methods and helping students develop their learning competence from knowing, understanding, applying, analysis, assessment, creation.

2). Applying technology in building storage systems and sharing resources from online learning models.

3). Accurate, effective evaluation in the feedback training results.

\section{The Criteria for Identifying IT Competence Framework in Online Teaching}

According to Keengwe \& Kidd, the course design process has five stages: (1) content design; (2) content development; (3) content implementation; (4) course assessment; (5) modify the content (Keengwe, J., \& Kidd, T. T., 2010).

Research on materials related to the application of IT competence in teaching and the criteria in assessing the application of IT in online teaching. In order to build the IT competence framework in line with the online education and to approach the international trend, the author shall base on the following principal bases: 1) IT Law; 2) Regulations on the application of IT in teaching by Ministry of Education and Training; 3) IT competence building program of Ministry of Information and Communications; 4) Output standard of students in the university training program; 5) ICT competence framework for teachers by 
UNESCO; 6) Characteristics of online learning model; 7) Technology factors in online teaching.

The bases are on the basis of identifying the components of using IT competence in online teaching.

Through research, practical assessment of the application of IT in teaching and the need for IT competence in online teaching, the author proposes a process for identify a competence framework in online teaching including 7 steps after:

(1) Retrieve documentation, identify bases for competence building

(2) Identifying the competence framework with component competences

(3) Build expressions for each component competence

(4) To take expert advice on the draft of competence framework

(5) Develop a detailed description of the levels corresponding to each expression in the competence framework

(6) To take expert advice about competence assessment criteria table

(7) Complete the competence framework and competence assessment criteria table

Identification of competence frameworks including indicators and criteria developed on the basis of research, analysis, assessment, control, and ask for experts who are educational researchers and knowledgeable teachers about field of applying IT in general teaching and online teaching in particular, along with some teachers have experience teaching in universities.

After receiving feedback from the experts, the using of IT competence framework was revised and further submitted for comments (repeat steps (3) <-> (4) and (6) <-> (7) of 7 steps on above). This process is repeated until there is high consensus from the experts.

The proposed framework for the use of IT in online teaching is reviewed on the assumptions set out in the selection of criteria, measurement values and assessment results. How to define criteria, measure the value of criteria, and evaluate effectiveness when applying the IT literacy framework in online teaching needs to be clarified. The identification of competence framework should cover common competences, specialty competence and managerial and managerial capacities in order to address the elements of mission objectives, standards and competence requirements in online training promote effectiveness in teaching methodology for competence development.

Through the research process, empirical analysis and get review of the professionals, the authors propose a framework for identifying the competence of using IT in online teaching for teachers, which of 7 component competences and 20 indices of corresponding expression.

Table 1

Identifying the IT competence framework for teachers in online teaching

\begin{tabular}{|c|c|}
\hline Component competencies & Expression index \\
\hline $\begin{array}{l}\text { 1. Competence to analyze and } \\
\text { assessment issues of using IT in } \\
\text { online teaching }\end{array}$ & $\begin{array}{l}\text { 1. Update and analyze the trends and policies of } \\
\text { applying IT in online teaching in the country and in } \\
\text { the world. }\end{array}$ \\
\hline & $\begin{array}{l}\text { 2. Proposing alternatives for applying IT in the } \\
\text { teaching process in accordance with objective and }\end{array}$ \\
\hline
\end{tabular}




\section{subjective conditions.}

2. Competence to use IT and the competence to use technicality medias in online teaching

3. Competence to use IT in designing, editing and building online teaching materials

4. Competence to use IT in exams, assessments and feedback on online learning results

$\begin{aligned} & \text { 5. Competence } \\ & \text { to use IT in } \\ & \text { management, } \\ & \text { organization }\end{aligned}$
online

6. Competence to use IT in the specialty training and pedagogical training of teachers

7. Competence to use IT in communication and products delivery
1. Use basic and advanced IT application programs.

2. Use utility programs with interactive IT in online teaching.

3. Use common technicality medias in teaching.

4. Use of assistive devices in online teaching.

5. Use proficient in external and online storage systems.

1. Use the search, mining and information management tools for teaching.

2. Use some software, tools to design, edit, modify and develop teaching materials.

3. Combining the application of IT to positive teaching methods and specific teaching methods of each subject according to the orientation of developing learner competence through online learning model.

1. Use software that supports the development, design and management of online exam questions banking.

2. Use multi-form of examinations and assessments to provide feedback on teaching and learning.

3. Promote the using of IT competency in the interaction of students in the online examination, assessment and feedback.

1. Use tools to manage the time, manage the resource, classroom organization.

2. Use tools to contact, monitor, manage and support students in the online course.

1. Use the internet and advanced search tools to update information related to your career fields.

2. Apply knowledge through specialized training to develop the applying IT competences.

3. Online work skills.

1. Use the services on the internet platform in reference, interchange, sharing of resources.

2. Multi-dimensional online learning support environment design.

Suggested 4 levels of determination for each expression are as follows:

Level 0: No competence: Teachers does not have this expression in teaching activities.

Level 1: Low level of competence: Teachers has the expression but not often (apply stereotypes, little criticism, own creation). 
Level 2: Average level of competence: Teachers expression quite often (with their own assessment, criticism and creativity).

Level 3: High level of competence: Teachers expression often (with their own assessment, criticism and creativity), can be guided and shared with others.

Assessment: The process of identifying the structure of using IT competence framework for teachers in online teaching is designed to exploit the application of IT in online teaching to meet the trend of education period with the public digitization, which is the core of IT and communication, addressing the main objectives of teaching in general and in online teaching in particular in the direction of competence development, in detail:

+ Knowledge and skills to use basic IT suitable for career objectives;

+ Integrate pedagogical knowledge and skills with technology to improve teaching and learning;

+ Apply technology to handle, store, respond and assessment learning outcomes;

+ Use technology to improve communication, collaboration and effectiveness in teaching;

+ Effectively exploit the application of IT in teaching in accordance with the period of digital technology.

\section{Assessment experimental results}

Conduct empirical evaluation through the organization of teaching on two object classes including: experimental classes that apply to teach the approach of developing IT and control classes with traditional teaching methods.

"Experimental class" denoted as EC, and "Control class" denoted as CC.

Through statistics, results of $F_{i}$ distribution table (number of students achieving $X_{i}$ score), $\mathrm{f}_{\mathrm{i}}$ frequency table $(\%)$ learning results, as follows:

Table 2

Table of $F_{i}$ scores for assessment of learning outcomes

\begin{tabular}{|c|c|c|c|c|c|c|c|}
\hline \multirow[b]{2}{*}{ Class } & \multirow{2}{*}{$\begin{array}{l}\text { Total } \\
\text { students }\end{array}$} & \multicolumn{5}{|c|}{ Number of exams with $X_{i}$ score } & \multirow[b]{2}{*}{$\bar{X}$} \\
\hline & & $\begin{array}{l}\text { A } \\
(8,5-10)\end{array}$ & $\begin{array}{l}\text { B } \\
(7,0-8,4)\end{array}$ & $\begin{array}{l}\mathrm{C} \\
(5,5-6,9)\end{array}$ & $\begin{array}{l}\mathrm{D} \\
(4,0-5,4)\end{array}$ & $\begin{array}{l}\text { F } \\
(0-3,9)\end{array}$ & \\
\hline EC & 38 & 18 & 16 & 3 & 1 & 0 & 7,0 \\
\hline $\mathbf{C C}$ & 37 & 10 & 12 & 12 & 3 & 0 & 6,4 \\
\hline
\end{tabular}

Table 3

Table of $f_{i}$ frequency (\%) learning results

\begin{tabular}{lllllll}
\hline \multirow{3}{*}{ Class } & \multirow{3}{*}{ Total students } & \multicolumn{5}{l}{ Frequency of the number of exams with $\mathbf{X}_{\mathbf{i}}$ score } \\
\cline { 3 - 7 } & & $\mathrm{A}$ & $\mathrm{B}$ & $\mathrm{C}$ & $\mathrm{D}$ & $\mathrm{F}$ \\
& & $(8,5-10)$ & $(7,0-8,4)$ & $(5,5-6,9)$ & $(4,0-5,4)$ & $(0-3,9)$ \\
\hline EC & 38 & 47,36 & 42,11 & 7,89 & 2,63 & 0,00 \\
CC & 37 & 27,03 & 32,43 & 32,43 & 8,11 & 0,00 \\
\hline
\end{tabular}




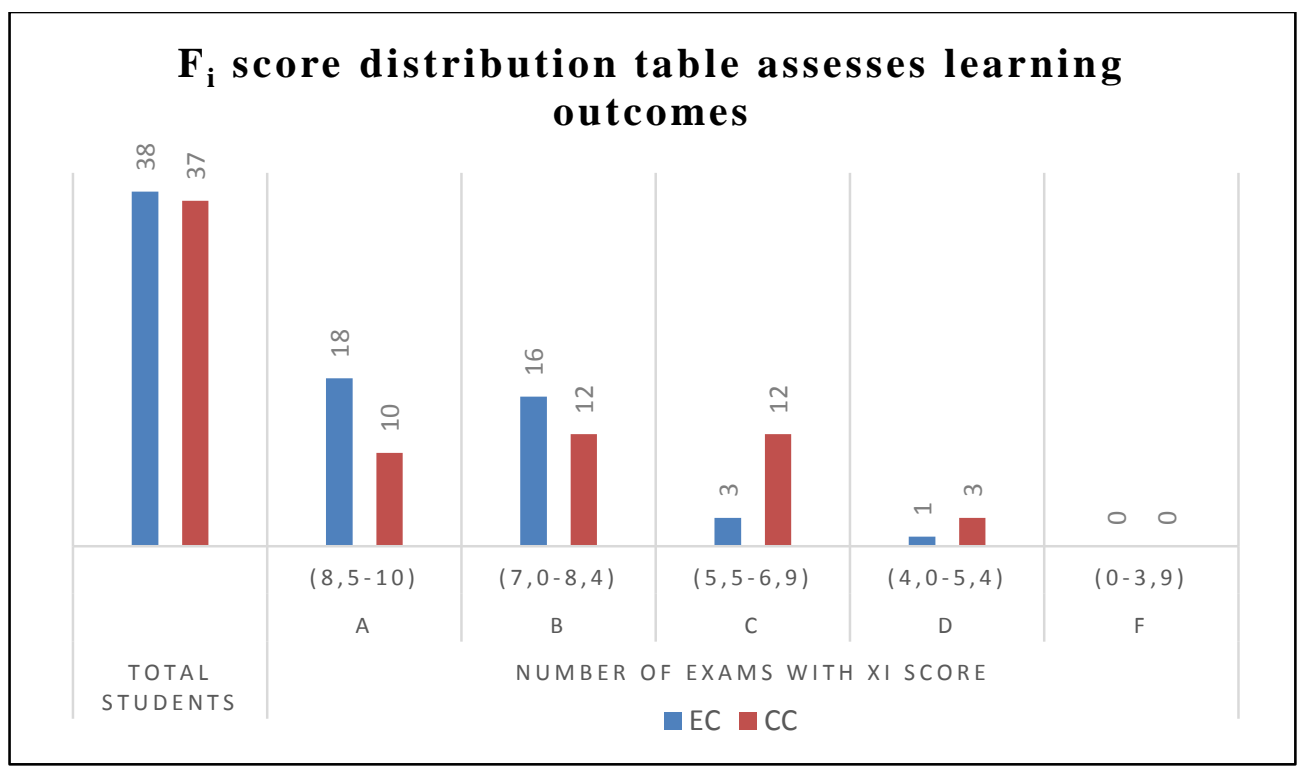

Figure 4: $F_{i}$ score distribution table assesses learning outcomes

The end of the course of the experimental class is higher than that of the pilot class (the average difference is 0,6 scores).

Experimental evaluation results confirmed the feasibility and effectiveness of teaching according to the approach of IT development. It can be concluded that students' learning efficiency has increased, the quality of teaching and learning of classes has been improved in the teaching process.

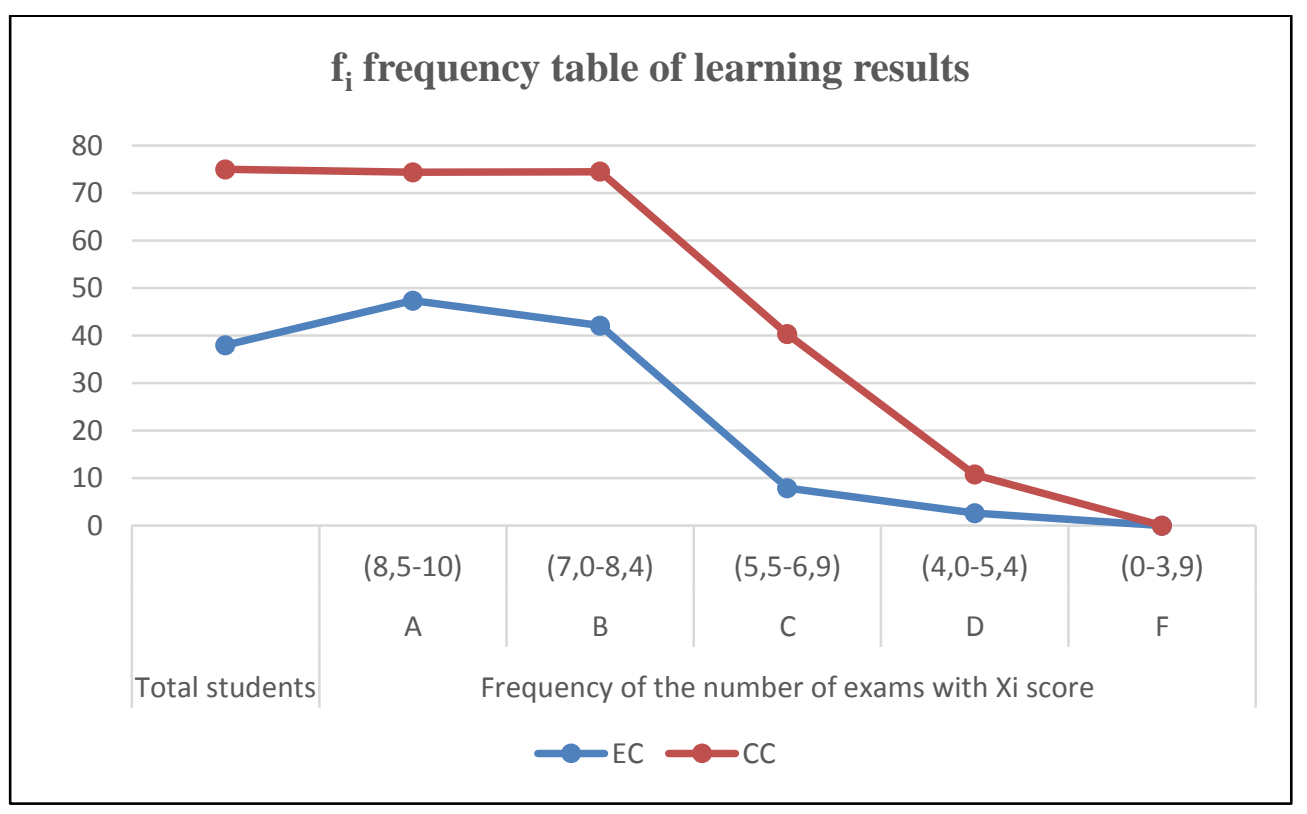

Figure 5: $\mathrm{f}_{\mathrm{i}}$ frequency table of learning results

\section{Forecasting ability to develop IT application competence in online teaching}

\section{Application of IT standards}

Focuses on the application of standards in online teaching, to show how each standard applies to anyone involved in teaching and management.

IT standards apply to all teaching environments, including the online environment. These include creating appropriate facilities, creating an appropriate learning environment, 
managing time and the presence of teachers and students.

\section{IT infrastructure}

Instructors in an online course need to understand that if a technical problem occurs, the learner may not be able to take the course. Teachers need to take measures to solve problems so that they can help learners follow the course fully.

Access to new technology, including equipment that can assist any learner. In order to provide the best possible result for learners, websites and other online information must be established in accordance with the universal design principles. Product design and environment must be implemented in such a way that everyone can use for the highest purpose without having to adjust or design special.

\section{Study environment}

An active learning environment encompasses a number of factors. In such an environment, learners can freely express their opinions and feel that they are always supported by their classmates and teachers. Learners should be involved in a variety of activities as well as collaborative exercises.

For the best learning outcomes, online learning environments need to have features that facilitate interaction and collaboration among learners so that they can create a good learning environment; Teachers need to be trained continuously, have sufficient time to prepare and participate in online courses, appropriate class sizes and a well-deserved salary.

\section{Study time}

Many older learners take online courses because they face many requirements due to work, family and study. They need to have clear timelines to be able to streamline work and family. As such, the timelines need to be clearly defined so that learners can organize (Shi, S., et al., 2006). Therefore, when there is a need for online activities at the same time, we need to plan ahead so that all learners can participate.

\section{Recognition the characteristics of the teacher and the learner}

Teachers and learners need to work together to create a social presence in the course where the learner is comfortable in interacting with other learners. Lecturer and usually also the course designer, has always been central to cognitive performance in online courses.

Assessment: Online education is an alternative to student learning to focus on critical and creative thinking. However, online courses are usually driven by technology (Callaway, S. K., 2012), and are more designed for the convenience of online systems and technology (Cole, M. T., 2014). To foster intellectual rigor and develop personal and informative perspectives, further research should explore how to use technology and software to engage students in repeated and ongoing conversations in many different online formats. With the advancement of technology the main factor is IT, the application of the role of many technological tools to promoting better social interaction and the growth of a learning community should be enhanced social media and virtual reality environments.

\section{DISCUSSIONS}

In order to implement the process of assessing and developing the IT application competence of teachers in teaching, the following points should be discussed and clarified so that the use IT competence is highly effective in online teaching:

A teaching content can not develop all the elemental competences so the teacher can select 
some appropriate elemental competence for assessment corresponding to the learning content with using IT competence.

The assessment of the development of competence is very elaborate and time-consuming, effort of teachers. Therefore, teachers can encourage self-assessment and peer assessment. At the same time, teachers can use some software to synthesize, manage and process the most effective assessment results in the process of organizing online teaching.

It is also important to consider the value of competencies as indicated by participants in the online expert survey, but not the explicit competencies required for success online teaching.

What is unknown about the hidden power of online education and technology and at the same time changing the way we design and manage our national education programs (Matthew, P., Marie, C., 2011; Wang, Y. D., 2014). This is considered with new techniques such as data mining and analytical learning, enabling the use of performance and behavioral data to improve learning not just to repeat the future of a program but in times of authenticity for current students is seen as an active learning method in online teaching when combined IT competence with new technologies for assessing and supporting instruction.

\section{CONCLUSION}

Identify barriers in teaching, new role of teacher in the online learning environment to stimulate reflection of effective strategies to enhance the success of teachers in the transition from the pedagogical platform online learning (Keengwe, J., Kidd, T. T., 2010) with development IT competence in teaching makes up the success factor of online teaching. Through the process of surveying, analyzing, evaluating development IT application competence in online teaching, we have gained some positive results with the research objectives set. The basic ability of applying IT in online teaching. Identify the criteria for using IT to help teachers identify the goals set for students in each module, from which to build content teaching and selection of teaching methods more appropriate. At the same time creating opportunities for students to participate and evaluate the process helps students recognize what to do and need to improve to achieve the best results. This approach is perfectly suited to the requirements of teaching oriented learners.

The next research of this paper is to propose a process for identifying IT competence criteria in online teaching. Conducting surveys, evaluations and building a set of criteria for assessing the using of IT competence framework in online teaching to identify behaviors, policies, and sets of guiding indicators for successful online teaching.

Availability of data and material: No

Funding: This study was funded by 0

Conflict of Interest: The authors declare that we have no conflict of interest Acknowledgments

This document received valuable contributions from the members of research's authors group, and many other researchers have made invaluable contributions. To all of them, we thank you very much.

\section{References}

Bennett, J., Hogarth, S., Lubben, F., Campbell, B., \& Robinson, A. (2006). ICT in science 
teaching. Technical report. In: Research Evidence in Education Library. London: EPPICentre, Social Science Research Unit, Institute of Education, University of London.

Callaway, S. K. (2012). Implications of online learning: Measuring Student Satisfaction and Learning for Online and Traditional Students. Insights to a Changing World Journal, 2. Distance Education, 35(3), 345-359.

Cole, M. T., Shelley, D. J., \& Swartz, L. B. (2014). Online Instruction, E-learning, and Student Satisfaction: A three year study. The International Review of Research in Open and Distance Learning, 15(6), 111-131.

Colwell, J. L., Jenks, C. F. (2004). Using Peer Evaluations and Teams in Online Classes. Paper presented at the, 1 T1C-5-T1C-9.

Craig, Blurton (2002). New Directions of IT-Use in Education, Paper presented at web http://www.unesco.org/education/educprog/lwf/dl/edit.pdf.

Gascoigne, C. \& Parnell, J. (2014). Distance education readiness assessments: An overview and application. Online Journal of Distance Learning Administration, XVII (IV).

Institute of Linguistics (2010). Vietnamese Dictionary, Polytechnic Dictionary Publisher.

International Society for Technology in Education (2008). ISTE Standards for Teachers. Paper presented at web http://www.iste.org/standards/standards-for-teachers.

Keengwe, J., \& Kidd, T. T. (2010). Towards Best Practices in Online Learning and Teaching in Higher Education. MERLOT Journal of Online Learning and Teaching, 6(2), 533541.

Matthew, P., and Marie, C. (2011). Assessing Learning in Online Education: The Role of Technology in Improving Student Outcomes. National Institute for Learning Outcomes Assessment.

National Assembly of Vietnam (2006). Information Technology Law.

Paula, M. B., Lawrence, C. R., Shannon. K., Janet, M., and Brian, F. R. (2010). The Identification of Competencies for Online Teaching Success. Journal of Asynchronous Learning Networks, 16(1).

Shi, S., Mishra, P., Bonk, C. J., Tan, S., \& Zhao Y. (2006). Thread theory: A Framework Applied to Content Analysis of Synchronous Computer Mediated Communication Data. International Journal of Instructional Technology \& Distance Learning, 3(3).

Sun, A., \& Chen, X. (2016). Online education and its effective practice: A research review. Journal of Information Technology Education: Research, 15,157-190.

The Education and Training Ministry, Vietnam (2015). The scheme on renewal of general education program and textbooks, Promulgated with the Prime Minister's Decision No. 404/QĐ-TTg, 2015.

UNESCO (2011). UNESCO ICT Competence Framework for Teachers, UNESCO.

UNESCO (2018). UNESCO ICT Competence Framework for Teachers, UNESCO.

VVOB (2011). Final Report on the workshop on "Building UNESCO's IT Program", Hanoi, Vietnam.

Wang, Y. D. (2014). Building Student Trust in Online Learning Environments. Journal of Distance Education. 35(3), 345-359. 